\title{
A study to achieve a fine surface finish in Wire-EDM
}

\author{
Y.S. Liao ${ }^{\text {a,* }}$, J.T. Huang ${ }^{b}$, Y.H. Chen ${ }^{\text {a }}$ \\ a Department of Mechanical Engineering, National Taiwan University, Taipei, Taiwan \\ ${ }^{\mathrm{b}}$ Department of Automatic Engineering, Kaoyuan Institute of Technology, Kaohsiung, Taiwan
}

Accepted 30 October 2003

\begin{abstract}
Many Wire-EDM machines have adopted the pulse-generating circuit using low power for ignition and high power for machining. However, it is not suitable for finishing process since the energy generated by the high-voltage sub-circuit is too high to obtain a desired fine surface, no matter how short the pulse-on time is assigned. For the machine used in this research, the best surface roughness $R_{\mathrm{a}}$ after finishing process is about $0.7 \mu \mathrm{m}$.

In order to obtain good surface roughness, the traditional circuit using low power for ignition is modified for machining as well. With the assistance of Taguchi quality design, ANOVA and $F$-test, machining voltage, current-limiting resistance, type of pulse-generating circuit and capacitance are identified as the significant parameters affecting the surface roughness in finishing process. In addition, it is found that a low conductivity of dielectric should be incorporated for the discharge spark to take place. After analyzing the effect of each relevant factor on surface roughness, appropriate values of all parameter are chosen and a fine surface of roughness $R_{\mathrm{a}}=0.22 \mu \mathrm{m}$ is achieved. The improvement is limited because finishing process becomes more difficult due to the occurrence of short circuit attributed to wire deflection and vibration when the energy is gradually lowered.
\end{abstract}

(c) 2004 Elsevier B.V. All rights reserved.

Keywords: Wire-EDM; Finish; Pulse-generating circuit; Surface roughness

\section{Introduction}

Accompanying the development of mechanical industry, the demands for alloy materials having high hardness, toughness and impact resistance are increasing. Nevertheless, those materials are difficult to be machined by traditional machining methods. Hence, non-traditional machining methods including electrolytic grinding, supersonic machining and electrical discharging machining (EDM) are applied. Wire-EDM process with a thin wire as an electrode transforms electrical energy to thermal energy for cutting materials. With this nature, alloy steels, conductive ceramics and aerospace parts can be machined irrespective to their hardness and toughness. Furthermore, Wire-EDM is capable of producing a fine, precise, corrosion-resistance and wear-resistance surface.

The Wire-EDMed surface consists of many craters caused by electrical sparks. The larger the electrical discharging energy, the worse the surface quality will be. A large en-

\footnotetext{
* Corresponding author. Tel.: +886-2-2362-6431; fax: +886-2-2363-1755.

E-mail address: liaoys@ntu.edu.tw (Y.S. Liao).
}

ergy will produce a rippled surface, change the structure and physical properties of materials, and result in cracks and residual stresses on the surface. The white layer caused by EDM process increases surface roughness, makes the surface become hard and brittle, and decreases the fatigue strength, corrosion and wear resistance of the workpiece. Eventually, the surface quality and life of the workpiece will be decreased as well. In addition, the electrolytic erosion, which may occur during the process, will result in more microcracks and a lower surface hardness.

In order to obtain a fine surface finish, several investigations using the low-conductivity dielectric to reduce the electrolytic current had been reported [1-5]. By analogy, the ac pulse generator is employed, and it is confirmed by experiments that a fine surface can be achieved $[2-4,6,7]$. This result is readily understood because the oxidation of work material due to electrolysis when dc pulse generator is applied is suppressed [8]. The white layer can be improved by increasing the slope of the current and pulse-on time [9]. Alternatively, it can be accomplished by reducing the peak current [10]. Practically, using a small energy and ac pulse-generating circuit after roughing process can lead to a fine surface finish [11]. 
To improve surface quality and achieve an optimal surface roughness in finishing process, the oxidation due to electrolysis should be prevented together with a lower energy input. Many traditional machines generally adopt the pulse-generating system with low power for ignition and high power for machining. It is not suitable for finishing process, since the energy generated by the high-voltage sub-circuit is too high to achieve a desired fine surface, no matter how short the pulse-on time is assigned. The purpose of this paper is to develop and study a pulse-generating circuit that can be switched for both roughing and finishing operations. Specifically, the traditional circuit using low power for ignition is modified for machining as well. Experiments were conducted to identify the significant factors affecting surface roughness. After analyzing the effect of each relevant factor on surface roughness, appropriate values of all parameters are chosen and a fine surface of roughness $R_{\mathrm{a}}=0.22 \mu \mathrm{m}$ is achieved for the machine used in this research.

\section{Experimental equipments}

The Wire-EDM machine used in this research was developed by Industrial Technology Research Institute (ITRI), Taiwan. The original ac pulse-generating circuit for roughing operation is shown in Fig. 1. In this research, the pulse-generating circuit for finishing operation was designed by modifying the original circuit, by way of removing the high-voltage discharging circuit. During the whole machining process, a low-voltage pulse-generating circuit was adopted for both ignition and machining as shown in Fig. 2. In addition, all other elements in the circuit such as resistance and capacitance are adjustable. Based on the structure of the full-bridge circuit, machining which uses ac alternating pulse-generating circuit, dc pulse-generating circuit of positive polarity (taking the wire as the anode) or dc pulse-generating circuit of negative polarity can be achieved by two sets of power switches.

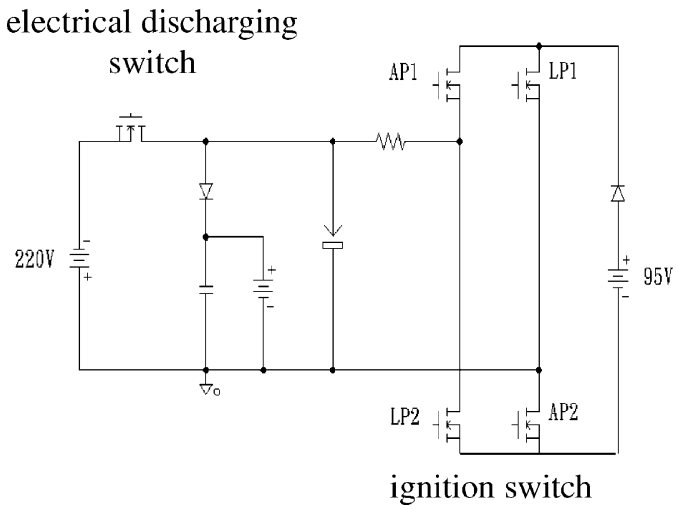

Fig. 1. Original Wire-EDM pulse-generating circuit.

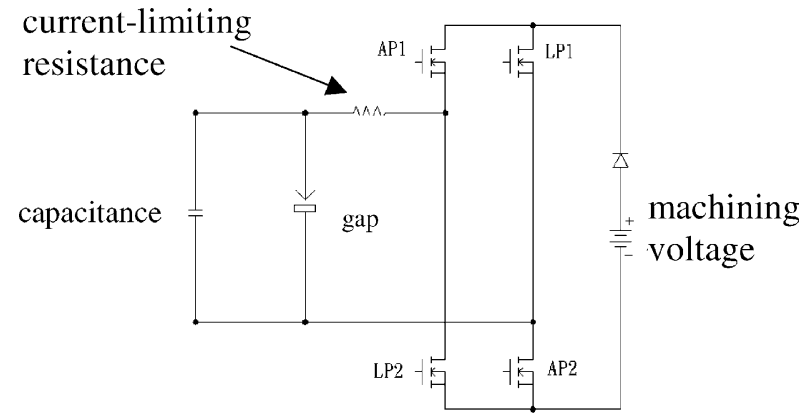

Fig. 2. Modified Wire-EDM pulse-generating circuit for finishing process.

\section{Influence of machining parameters on surface roughness}

\subsection{Experimental design and planning}

In this research, the main machining performance to be measured is machined surface roughness $\left(R_{\mathrm{a}}\right)$. A fine surface was expected by adjusting machining parameters in finishing stage. Considering actual machining condition, those controlling factors, including type of pulse-generating circuit (PS), conductivity of the dielectric $(K)$, resistance in the circuit $(R)$, capacitance in the circuit $(C)$, applied voltage $(V)$, feed rate of the table $(F)$ and pulse-off time $\left(T_{\text {off }}\right)$, were chosen to conduct the experiments. To reduce the number of experiments, the L18 mixed orthogonal array table of Taguchi quality design was adopted. Those level settings of each factor in the experiments are shown in Table 1. ac pulse-generating circuit represents that the electrode of the wire and the workpiece are changing alternately for ignition and machining. dc pulse-generating circuit of positive polarity set the wire as the anode and the workpiece as the cathode in finishing operation. Regarding pulse-off time, the same values are set for both the normal discharging pulse-off time and arc pulse-off time.

\subsection{Experimental results}

ANOVA and $F$-test were used to analyze the experimental results $\left(R_{\mathrm{a}}\right)$ as shown in Table 2 . The $\mathrm{S} / \mathrm{N}$ values of

Table 1

Settings of Taguchi experimental levels

\begin{tabular}{lrrr}
\hline Machining parameters & \multicolumn{2}{l}{ Level } & \\
\cline { 2 - 4 } & \multicolumn{1}{c}{1} & 2 & 3 \\
\hline Pulse-generating circuit $(\mathrm{PS})$ & $\mathrm{ac}$ & $\mathrm{dc}$ & \\
Conductivity of dielectric, $K(\mu \mathrm{S} / \mathrm{cm})$ & 15 & 30 & 45 \\
Resistance in the circuit, $R(\Omega)$ & 25 & 50 & 75 \\
Capacitance in the circuit, $C(\mathrm{nF})$ & 0 & 10 & 20 \\
Applied voltage, $V(\mathrm{~V})$ & 100 & 125 & 150 \\
Feed rate of the table, $F(\mathrm{~mm} / \mathrm{min})$ & 2 & 3 & 4 \\
Pulse-off time, $T_{\text {off }}(\mu \mathrm{s})$ & 4 & 6 & 8 \\
Error, $e$ & 1 & 2 & 3 \\
\hline
\end{tabular}


Table 2

Influence of machining parameters on surface roughness

\begin{tabular}{|c|c|c|c|c|c|c|c|}
\hline \multirow[t]{2}{*}{ Machining performance } & \multicolumn{7}{|c|}{ Machining parameters } \\
\hline & PS & $K$ & $R$ & $C$ & $V$ & $F$ & $T_{\text {off }}$ \\
\hline Surface roughness & Significant factor & & Significant factor & Sub-significant factor & Significant factor & & \\
\hline
\end{tabular}

machining parameters on surface roughness were indicated in Fig. 3. It is noted that surface roughness has the characteristic of "smaller is better". Hence, a larger S/N values value means a smaller value of surface roughness. Looking at Fig. 3 and Table 2, we can readily realize the variant trend of significant factors on surface roughness as discussed in the following sections.

\subsection{The influence of various factors on $R_{\mathrm{a}}$}

\subsubsection{Voltage and resistance}

Most related researches of pulse-generating circuit for roughing operation pointed out that the dominant factor affecting surface roughness is pulse-on time $\left(T_{\text {on }}\right)$, because the surface roughness depends on the size of spark crater. A shallow crater together with a larger diameter leads to a better workpiece surface roughness. To obtain a flat crater, it is important to control the electrical discharging energy at a smaller level by setting a small pulse-on time $\left(T_{\text {on }}\right)$ since most Wire-EDM machines were designed to discharge with the electrical discharging current proportional to the pulse-on time. A large discharging energy will cause violent sparks and results in a deeper erosion crater on the surface. Accompanying the cooling process after the spilling of molten metal, residues will remain at the periphery of the crater to form a rough surface. In this research, pule-on time in finishing process was set to a constant value of $0.05 \mu \mathrm{s}$. Hence, the size of a discharging crater depends exclusively on the pulse-generating circuit providing a discharging spark. In the designed circuit, a small voltage and a large resistance were used so as to provide a small discharging energy and hence to produce a good surface.

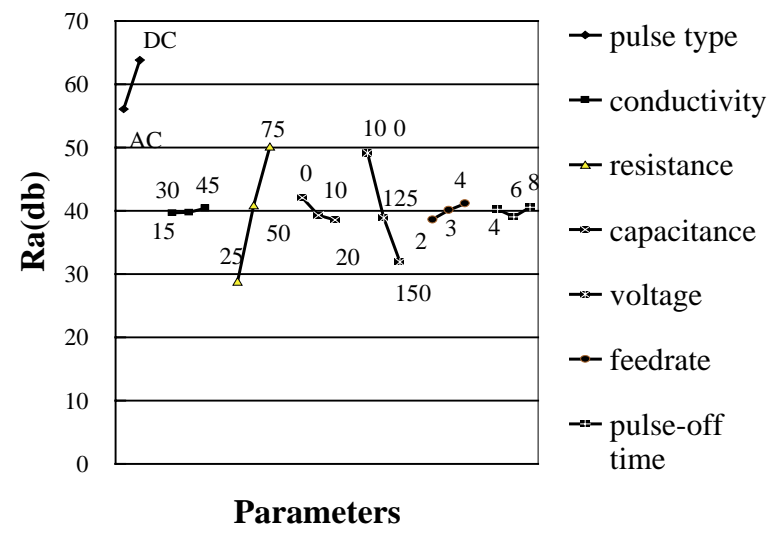

Fig. 3. S/N values of surface roughness at different machining parameters.

\subsubsection{Type of pulse-generating system}

From the experimental results, it was found that measured surface roughness using dc pulse-generating circuit of positive polarity (wire electrode is anode and work material is cathode) is better than that using ac pulse-generating circuit. Different from the pulse-generating circuit used in roughing process, the polarity remains unchanged for both ignition and machining in this research, instead of changing it to negative polarity while machining. To sum up, machining with different polarity results in different sizes of the crater and the surface roughness.

The relationship between the erosion rate of the anode or cathode and pulse-on time was schematically illustrated in Fig. 4. It is apparent that cathode erosion rate is lower than anode erosion rate while machining with a quite small pulse-on time, such as $T_{\text {on }}<0.5 \mu$ s. It is inferred that the crater of a single spark produced on the cathode surface will be smaller than that on the anode surface. Hence, the pulse-generating circuit for finishing operation in this research adopted dc pulse-generating circuit of positive polarity which set wire as the anode. From surface roughness point of view, it is superior to ac pulse-generating circuit which is exchanging anode and cathode alternately.

\subsubsection{Capacitance}

As it is easily known from the experimental results, surface quality will be better without using capacitance in the circuit. The waveforms of discharging voltage and current for different capacitance are shown in Fig. 5. In this figure, curve 1 represents the voltage of the pulse, curve 2 the total current flowing across the machining gap and capacitance, and curve 3 the actual machining current across the gap, which is the upper branch of the total current and is about half of the total current. It can be seen from the discharging

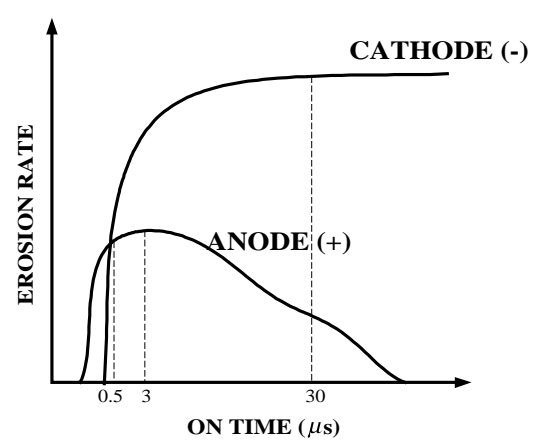

Fig. 4. Erosion rate of anode and cathode vs. pulse-on time. 


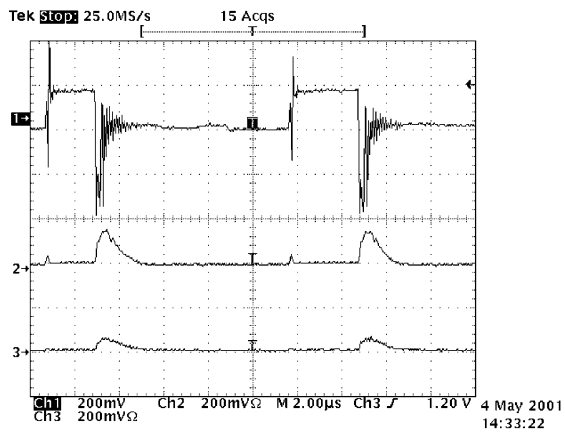

(a) $\mathrm{C}=0$

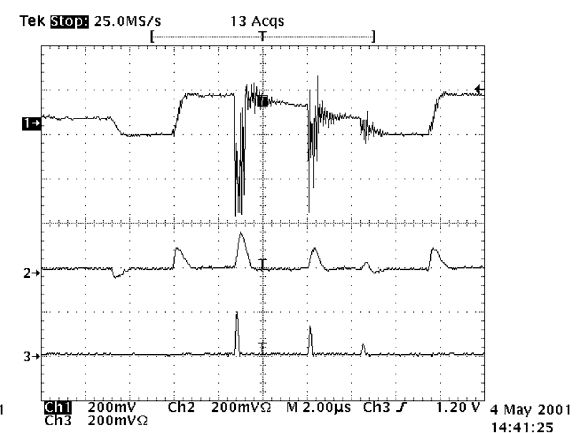

(b) $\mathrm{C}=10 \mathrm{nF}$

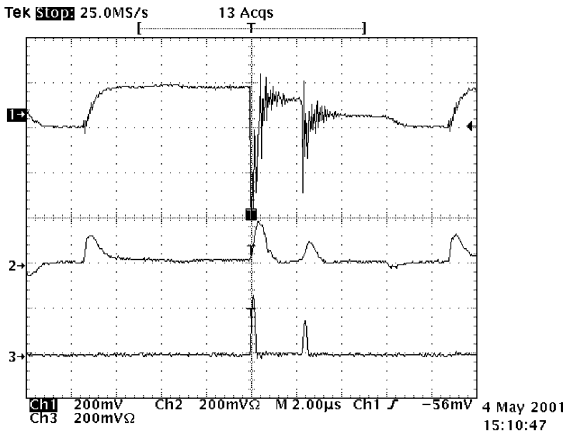

(c) $\mathrm{C}=20 \mathrm{nF}$

Fig. 5. Waveforms of discharging voltage and current at different capacitance values ( $V$ : $100 \mathrm{~V} /$ div.; $I: 4 \mathrm{~A} /$ div.; time scale: $2 \mu \mathrm{s} /$ div.) (1: pulse voltage; 2: total current; 3 : actual machining current).

current in Fig. 5 that the waveform of discharging current in actual machining is flatter when there is no capacitance in the circuit. The waveform with capacitance was sharper, and the larger the capacitance, the larger is the peak current. This can also be verified from the appearance of sparks as they are brighter. It is also noted that there is a pulse-off time of $8 \mu \mathrm{s}$ after discharging for the gap to recover to its initial insulated condition. But the discharging voltage did not approach zero level due to the energy continuously supplied by this extra capacitance. Hence discharges of non-uniform energy still take place during the pulse-off time. Based on these observations, it is inferred that a larger capacitance will result in deeper craters and worsen machined surface roughness.

\subsubsection{Dielectric}

Although the conductivity of dielectric is not a significant factor on $R_{\mathrm{a}}$, it may however result in unsuccessful discharging in finishing process. Fig. 6 shows the waveforms of discharging voltage and current for different conductivity of the dielectric, where in this figure curve 1 and curve 2 stand for discharging voltage and discharging current, respectively. The waveforms of all three figures in Fig. 6 are similar. But it can be seen that there is "leaking" current at the stage when ignition voltage is applied, especially for conductivity equals to 30 and $45 \mu \mathrm{S} / \mathrm{cm}$. This leaking current is known as electrolytic current. Applying extra voltage between two electrodes will increase the driving force of chemical reaction and facilitate electrolysis process. This in

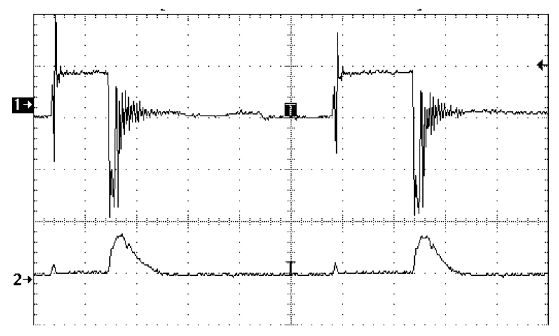

(a) $\mathrm{K}=15 \mu \mathrm{S} / \mathrm{cm}$

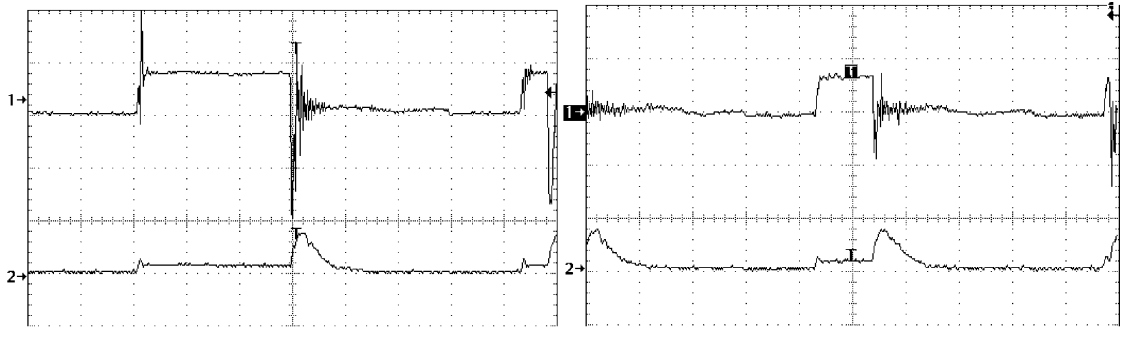

(b) $\mathrm{K}=30 \mu \mathrm{S} / \mathrm{cm}$

(c) $\mathrm{K}=45 \mu \mathrm{S} / \mathrm{cm}$

Fig. 6. Waveforms of discharging voltage and current at different conductivities ( $V: 100 \mathrm{~V} /$ div.; $I: 4 \mathrm{~A} / \mathrm{div} . ;$ time scale: $2 \mu \mathrm{s} / \mathrm{div}$.) (1: discharging voltage; 2: discharging current).

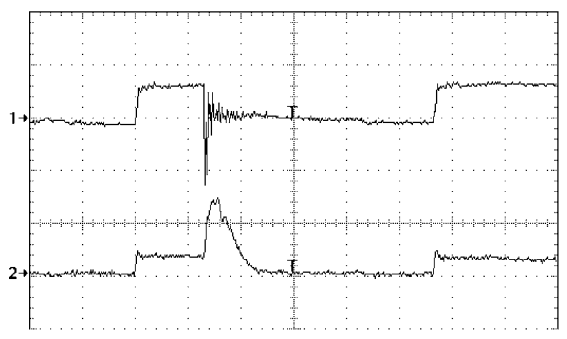

(a) $\mathrm{R}=25 \Omega$

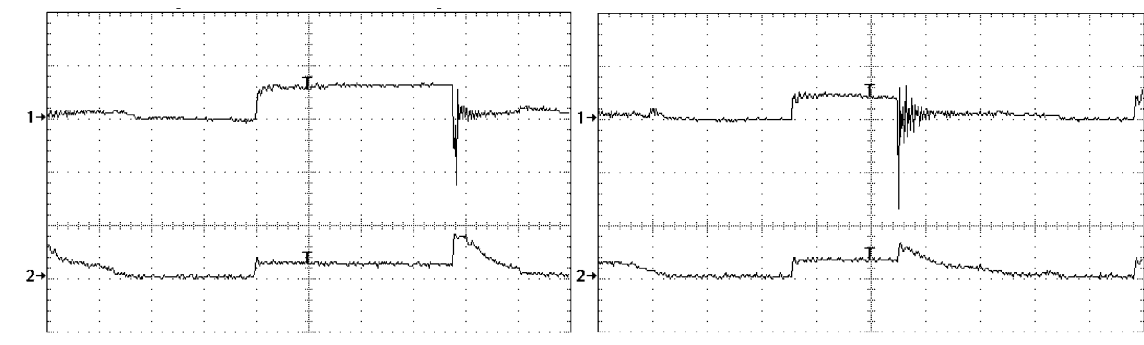

(b) $\mathrm{R}=50 \Omega$

(c) $\mathrm{R}=75 \Omega$

Fig. 7. Waveforms of discharging voltage and current at different resistance values (V: $100 \mathrm{~V} / \mathrm{div}$.; $I$ : $2 \mathrm{~A} / \mathrm{div}$.; time scale: $2 \mu \mathrm{s} / \mathrm{div}$.) (machining voltage: $100 \mathrm{~V}$, conductivity: $45 \mu \mathrm{S} / \mathrm{cm}$ ) (1: discharging voltage; 2 : discharging current). 
turn causes the electrolytic current to form due to the flow of electrons and ions. Since electrolytic current is increased proportionally with the increase of conductivity of dielectric as shown in Fig. 6, oxidation due to electrolysis will become more serious.

The ac pulse-generating circuit and dc pulse-generating circuit of positive polarity are used in our experiments, hence no electrolysis is encountered. Nevertheless, discharging spark may not be able to take place under the dielectric of high conductivity. Discharging energy decreases with the increase of the resistance, but the electrolytic current still remains at same level under the circumstance of same conductivity as shown in Fig. 7. When a large resistance is used, finishing sparks are difficult to occur for the reason that discharging current is smaller than the electrolytic current. Hence, the conductivity of dielectric should be set below about $15 \mu \mathrm{S} / \mathrm{cm}$ to ensure the occurrence of sparks for our machine.

\section{Approach to achieving a fine surface}

Based on the above analysis, the significant factors affecting surface roughness in finishing are noted as machining voltage, current-limiting resistance, capacitance and type of pulse-generating circuit together with the use of a dielectric of lower conductivity. Experiments of finishing operation employing the dc pulse-generating circuit of positive polarity having the voltage of $100 \mathrm{~V}$ and no capacitance are conducted under the dielectric having a conductivity of $15 \mu \mathrm{S} / \mathrm{cm}$. By gradually increasing the values of resistance the measured surface roughness is depicted in Fig. 8. A fine surface of roughness $R_{\mathrm{a}}=0.22 \mu \mathrm{m}$ can be obtained eventually using dc pulse-generating circuit of positive polarity and a low discharging energy. Although, a large resistance, such as $125 \Omega$, can further decrease the discharging energy. However, it also prevents sparks from taking place and results in discontinuous discharging and leaves a wire mark on the machined surface. Similarly, a small voltage like $75 \mathrm{~V}$

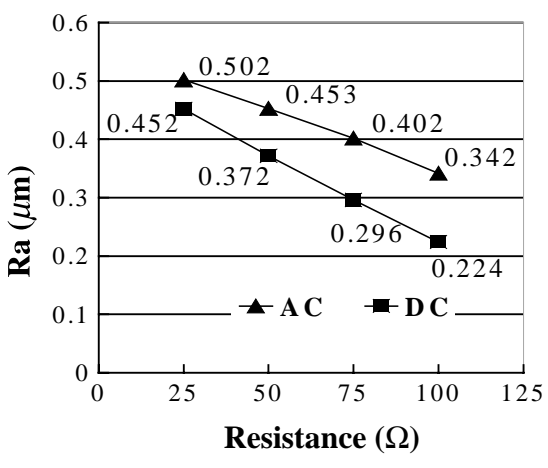

Fig. 8. Surface roughness vs. resistance for ac and dc pulse-generating circuits.

has the same effect. Machining at a smaller voltage needs a closer gap between wire and workpiece to ensure the occurrence of discharging spark. But, when the wire is close to the workpiece, the electrostatic force between the anode and cathode will increase. This attractive force will increase wire deflection and make it difficult to operate in finishing process. Hence, it is postulated to pre-fix the voltage of the circuit for finishing operation to $100 \mathrm{~V}$. The resistance is then adjusted gradually until a fine surface is achieved. For comparison purpose, the ac pulse-generating circuit is tested and the results are shown in Fig. 8 as well. Under the same discharging energy, a surface quality of roughness $R_{\mathrm{a}}=0.34 \mu \mathrm{m}$ is obtained.

The machining operations for the above-mentioned experiments using dc pulse-generating circuit and positive polarity are given in Table 3 . In the table, PS1 and PS2 represent the original pulse-generating circuit for roughing operation and the modified pulse-generating circuit for finishing operation, respectively. Cutting depth is the distance that the wire moves towards workpiece after each machining operation. The fine surface of $R_{\mathrm{a}}=0.22 \mu \mathrm{m}$ was obtained after 13 machining operations. It should be noted that the effects of pulse-generating system and related parameters on machined

Table 3

Steps of finishing process

\begin{tabular}{|c|c|c|c|c|c|c|c|c|}
\hline $\begin{array}{l}\text { Machining } \\
\text { operations }\end{array}$ & $\begin{array}{l}\text { Pulse } \\
\text { type }\end{array}$ & $T_{\text {on }}(\mu \mathrm{s})$ & $T_{\text {off }}(\mu \mathrm{s})$ & $\begin{array}{l}\text { Machining } \\
\text { voltage }(\mathrm{V})\end{array}$ & $\begin{array}{l}\text { Current-limiting } \\
\text { resistance }(\Omega)\end{array}$ & $\begin{array}{l}\text { Feed rate } \\
(\mathrm{mm} / \mathrm{min})\end{array}$ & $\begin{array}{l}\text { Cutting } \\
\text { depth }(\mu \mathrm{m})\end{array}$ & $R_{\mathrm{a}}(\mu \mathrm{m})$ \\
\hline 1 & PS1 & 0.8 & 10 & 220 & - & 4.2 & - & 2.83 \\
\hline 2 & PS1 & 0.2 & 8 & 220 & - & 4 & 25 & - \\
\hline 3 & PS1 & 0.2 & 8 & 220 & - & 4 & 20 & 1.63 \\
\hline 4 & PS1 & 0.05 & 8 & 220 & - & 4 & 10 & - \\
\hline 5 & PS1 & 0.05 & 8 & 220 & - & 4 & 10 & 0.702 \\
\hline 6 & PS2 & 0.05 & 8 & 100 & 25 & 4 & 8 & - \\
\hline 7 & PS2 & 0.05 & 8 & 100 & 25 & 4 & 8 & 0.452 \\
\hline 8 & PS2 & 0.05 & 8 & 100 & 50 & 4 & 5 & - \\
\hline 9 & PS2 & 0.05 & 8 & 100 & 50 & 4 & 3 & 0.372 \\
\hline 10 & PS2 & 0.05 & 8 & 100 & 75 & 4 & 2 & - \\
\hline 11 & PS2 & 0.05 & 8 & 100 & 75 & 4 & 2 & 0.296 \\
\hline 12 & PS2 & 0.05 & 8 & 100 & 100 & 4 & 1 & - \\
\hline 13 & PS2 & 0.05 & 8 & 100 & 100 & 4 & 0 & 0.224 \\
\hline
\end{tabular}




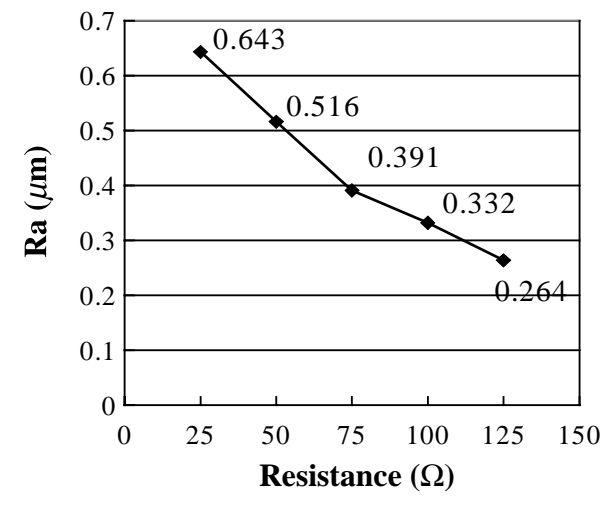

Fig. 9. Surface roughness vs. resistance at $150 \mathrm{~V}$.

surface roughness in finishing operation are the main concern of this paper; the approach to reduce the number of machining operations is not considered but is underway.

To check if a higher power incorporated with a larger resistance can lead to a better machined surface roughness, experiments using a high voltage of $150 \mathrm{~V}$, dc pulse-generating circuit of positive polarity and gradually decreasing discharging energy were carried out. The result is shown in Fig. 9. Compared with the previous experiment, a successful ignition can be more easily accomplished in this case even when the wire is farther away from the workpiece. However, discharging sparks were noted to be weak and discontinuous, and hence moving wire closer to workpiece during machining is essential. Similarly, a large resistance above $150 \Omega$ would reduce the discharging energy and result in weak discharging sparks as well. This causes finishing process difficult to proceed even though the wire is moved very close to the workpiece.

Fig. 10 shows the variation of the measured surface roughness along two different directions on the same workpiece with respect to resistance of a dc pulse-generating circuit of positive polarity and a voltage of $100 \mathrm{~V}$. It is found that the surface roughness along the wire feeding direction is superior to that along the machining direction. In the finishing process, the machined surface along wire feeding direction

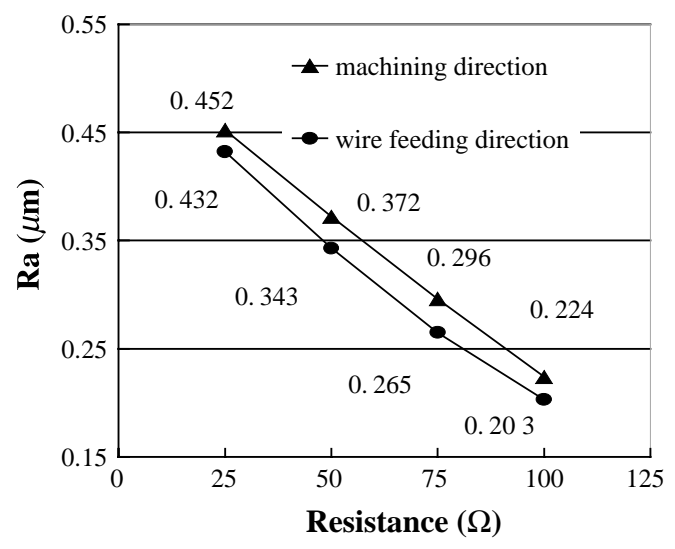

Fig. 10. Surface roughness vs. resistance along two different directions.

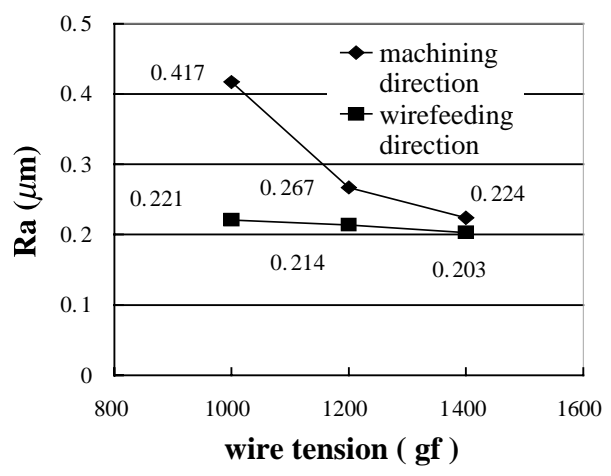

Fig. 11. Surface roughness vs. wire tension along two different directions.

is formed mainly by the accumulated craters only. But that along machining direction would be affected additionally by the motion, vibration and deflection of the wire. Hence, the measured surface roughness along wire feeding direction can better reflect the ideal value. Fig. 11 shows the measured surface roughness along two different directions with respect to wire tension using a dc pulse-generating circuit of positive polarity, a voltage of $100 \mathrm{~V}$ and a resistance of $100 \Omega$. It can be seen that wire vibration becomes more serious as wire tension decreases, but the variation along the wire feeding direction is small. This also infers that a fine surface can be achieved by using a stable and large wire tension.

\section{Conclusions}

To obtain good surface roughness, the traditional circuit using low power for ignition is modified for machining as well. With the assistance of Taguchi quality design, ANOVA and $F$-test, machining voltage, current-limiting resistance, type of pulse-generating circuit and capacitance are identified as the significant parameters affecting the surface roughness in finishing process. A dc pulse-generating circuit of positive polarity (wire electrode is set as anode) can achieve a better surface roughness in finishing operation. In addition, it is found that a low conductivity of dielectric should be incorporated for the discharge spark to take place.

After analyzing the effect of each relevant factor on surface roughness, appropriate values of all parameter are chosen and a fine surface of roughness $R_{\mathrm{a}}=0.22 \mu \mathrm{m}$ is achieved. The improvement is limited because finishing process becomes more difficult due to the occurrence of short circuit attributed to wire deflection and vibration when the energy is gradually lowered.

\section{Acknowledgements}

The support (NSC 92-2212-E-244-005) of National Science Council in Taiwan is greatly acknowledged. 


\section{References}

[1] I. Ogata, Y. Mokoyama, Residual stress on surface machined by wire electric discharge, Int. J. Jpn. Soc. Prec. Eng. 25 (4) (1991) 273-278.

[2] K. Masui, T. Sone, K. Demizu, The microhardness on Wire-EDM's surface, J. Jpn. Soc. Prec. Eng. (JSPE) 57 (1) (1991) 138-143.

[3] K. Masui, T. Sone, Surface integrity and its improvement of EDM, J. Jpn. Soc. Prec. Eng. (JSPE) 57 (6) (1991) 13-16.

[4] K. Masui, T. Sone, The electrolytic corrosion on Wire-EDMed surface, J. Jpn. Soc. Prec. Eng. (JSPE) 54 (6) (1988) 160-165.

[5] Y. Uno, T. Nakajima, M. Okada, Fundamental study on electrical discharge machining in deionized water, EDM Technol. 1 (1993) 3-11.

[6] H. Minani, K. Masui, H. Hagino, Coloring method of titanium alloy using EDM process, in: Proceedings of the 11th International
Symposium on Electro-Machining (ISEM-11), 1998, pp. 503-512.

[7] Y. Suziki, M. Kishi, Improvement of surface roughness in Wire EDM, in: Proceedings of the Ninth International Symposium on Electro-Machining (ISEM-9), 1989, pp. 80-83.

[8] T. Magara, H. Yamada, S. Sato, T. Yatomi, K. Kobayashi, Improvement of surface quality by non-electrolysis Wire-EDM, J. Jpn. Soc. Prec. Eng. (JSPE) 59 (7) (1993) 1157-1162.

[9] F. Balleys, Ch. Piantchenko, Surface integrity of materials machined by Wire EDM machines, EDM Technol. 4 (1993) 3-6.

[10] R.E. Williams, K.P. Rajurkar, Study of wire electrical discharge machined surfaced characteristics, J. Mater. Process. Technol. 28 (1991) 127-138.

[11] Y. Kaneko, T. Toyonaga, D. Sadamitsu, T. Kuloda, Method and apparatus for achieving a fine surface finish in Wire-cut EDM, US Patent 6130395 (2000). 